\title{
ANALISIS PEMBELAJARAN PENDIDIKAN AGAMA ISLAM KURIKULUM 2013 BAGI ANAK BERKEBUTUHAN KHUSUS
}

\author{
Received: 04-05-2020 \\ Revised: 29-05-2020 \\ Accepted: 25-06-2020
}

\section{Dinda Zulaikhah ${ }^{1}$,Akhmad Sirojuddin ${ }^{2}$ Andika Aprilianto ${ }^{3}$}

Fakultas Tarbiyah Institut Pesantren KH Abdul Chalim Mojokerto Indonesia ${ }^{1,2,3}$

Email: Zulaikhahadinda278@gmail.com, Akhmadsirojuddin86@gmail.com, andika4ikhac@gmail.com

Keywords: Islamic

\section{Education,}

Curriculum,

Children with

Disability

\begin{abstract}
This study aims to analyze the 2013 curriculum on educational materials especially for children with special needs. The method used in this research is literature study by analyzing the results of previous research and elaborating in content analysis. The result of this research is the need for a special curriculum for Islamic religious education material for special school children. It needs material simplification and a simple evaluation because not all special school children are able to evaluate according to general material. Teachers need patience in carrying out the learning process and also need to master various methods so that children don't get bored.
\end{abstract}


Tafkir: Interdisciplinary Journal of Islamic Education

Vol.1, No.1, June 2020, , DOI:

Hal: 54-71, E-ISSN :

\section{PENDAHULUAN}

Kurikulum merupakan hal yang sangat penting dalam pendidikan. Didalam kurikulum, termuat rencana dan pedoman-pedoman agar dapat berhasil mencapai tujuan pendidikan. Adapun tujuan pendidikan yang tertulis dalam UU No.20 Tahun 2013 tentang Sistem Pendidikan Nasional bahwasanya tujuan pendidikan nasional adalah untuk mengembangkan potensi peserta didik agar menjadi manusia yang beriman dan bertakwa kepada Tuhan Yang Maha Esa, berakhlak mulia, sehat, berilmu, cakap, kreatif, mandiri, dan menjadi warga Negara yang demokratis serta bertanggung jawab1.

Kurikulum telah mengalami berbagai perkembangan dan penyempurnaan. Hal tersebut agar pendidikan dapat semakin baik kedepannya dan disesuaikan berdasarkan perkembangan zaman. Hingga kini kurikulum terbaru yaitu kurikulum 20132. Penerapan kurikulum 2013 ini pada semua mata pelajaran termasuk pada mata pelajaran pendidikan agama islam. Namun ternyata, pada awal diresmikannya kurikulum 2013, kurikulum terbaru ini belum sepenuhnya dapat diterapkan secara luas di Indonesia ${ }^{34}$. Masih banyak sekali sekolah-sekolah yang menggunakan kurikulum lama (KTSP) hingga beberapa tahun sampai pada akhirnya siap berganti menerapkan kurikulum 2013. Kurikulum 2013 memiliki 5 tahapan yang dirasa sangat berat untuk konteks sekolah yang mana belum siap untuk melaksanakannya, terutama pada sekolah luar biasa (SLB) 5 .

Pada sekolah luar biasa, meskipun peserta didiknya berbeda dari sekolah reguler pada umumnya, kurikulum 2013 juga tetap perlu diterapkan. Hal tersebut

1 Yunus Abidin, Desain Sistem Pembelajaran Dalam Konteks Kurikulum 2013, Cetakan kesatu (Bandung: Refika Aditama, 2014).

2 Abdullah Idi, Pengembangan kurikulum: teori dan praktik, 2nd ed. (Jakarta: Raja Grafindo Persada, 2016).

3 Muhammad Anas Maarif and Muhammad Husnur Rofiq, ‘Pola Pengembangan Kurikulum Pendidikan Pesantren Berkarakter : Studi Implementasi Pendidikan Berkarakter di Pondok Pesantren Nurul Ummah Mojokerto' 13 (2018): 16.

4 Muhammad Anas Ma`arif and Ibnu Rusydi, 'IMPLEMENTASI PENDIDIKAN HOLISTIK DI PONDOK PESANTREN AMANATUL UMMAH MOJOKERTO', EDUKASI: Jurnal Penelitian Pendidikan Agama Dan Keagamaan 18, no. 1 (27 April 2020), https://doi.org/10.32729/edukasi.v18i1.598.

5 Nurul Indana, 'Penerapan Kurikulum Terintegrasi Dalam Mengembangkan Mutu Belajar Siswa (Studi Kasus Di Sma Darul 'Ulum 1 Unggulan Bppt Jombang)', Nidhomul Haq: Jurnal Manajemen Pendidikan Islam 3, no. 2 (17 October 2018): 121-47, https://doi.org/10.31538/ndh.v3i2.80. 
Dinda Zulaikhah, Andika Aprilianto

merupakan wujud tidak adanya pembedaan atau diskriminasi terhadap anak-anak luar biasa dalam hal pendidikan. Karena pada hakikatnya setiap manusia memiliki hak-hak dasar dan setiap anak adalah anugerah dari Tuhan yang dibekali dengan potensi dan bakat-bakat, meskipun mereka memiliki keterbatasan atau biasa disebut dengan anak berkebutuhan khusus dan anak luar biasa6.

Begitu pula dalam agama islam yang merupakan rahmatan lil 'alamin atau rahmat bagi seluruh alam. Artinya islam pun tidak membedakan secara negatif (diskriminasi) umat manusia dari segi fisik atau kecerdasannya, melainkan yang dinilai ialah tingkat ketakwaannya pada Allah SWT7. Oleh karena itu penting bagi anak-anak luar biasa untuk tetap mendapatkan pendidikan sebagaimana seharusnya, khususnya pendidikan agama islam agar nilai-nilai islam dapat tertanam dan diterapkan oleh mereka sejak dini sehingga mereka dapat menjadi manusia yang bertakwa .

Pendidikan Agama Islam bagi anak-anak berkebutuhan khusus tentunya sangat diperlukan agar mereka dapat menjalankan syariat agama dan bertakwa kepada Allah SWT. Terlebih di dalam islam sendiri juga telah terdapat rukhsah atau kemudahan bagi setiap hambanya bila mereka memiliki kendala-kendala dalam menjalankan ibadah. Bahkan juga telah terdapat ilmu yang secara khusus membahas mengenai syariat-syariat bagi orang-orang dengan kebutuhan khusus ini yang disebut dengan Fiqih Disabilitas.

Maka dari itu, tidak ada alasan untuk tidak belajar agama. Hal tersebut menjadi kewajiban para orang tua dan para pendidik untuk berusaha memasukkan nilai-nilai islami pada anak-anak dengan kebutuhan khusus dan mengamalkannya. Atas latar belakang itulah, artikel ini ditulis guna mengetahui dan memahami

${ }^{6}$ Muhammad Husnur Rofiq and Prastio Surya, 'Model Pembentukan Karakter Berbasis Tasawuf Akhlaqi', Ilmuna: Jurnal Studi Pendidikan Agama Islam 1, no. 2 (2019): 65-81, https://jurnal.stituwjombang.ac.id/index.php/ilmuna/article/view/109; Muhammad Anas Ma'arif and Ari Kartiko, 'Fenomenologi Hukuman di Pesantren: Analisis Tata Tertib Santri Pondok Pesantren Daruttaqwa Gresik', Nadwa 12, no. 1 (22 June 2018): 181-96, https://doi.org/10.21580/nw.2018.12.1.1862.

7 Munawar Rahmat, 'Model Perkuliahan Pendidikan Agama Islam Yang Damai, Moderat, dan Toleran', Nadwa 12, no. 1 (22 June 2018): 39-64, https://doi.org/10.21580/nw.2018.12.1.2180.

${ }^{8}$ Rahmat Rahmat, 'Liberalisme Dalam Pendidikan Islam (Implikasinya Terhadap Sistem Pembelajaran Agama Islam Di Sekolah)', Nidhomul Haq: Jurnal Manajemen Pendidikan Islam 1, no. 2 (2016): 70-88, https://doi.org/10.31538/ndh.v1i2.10.

Vol.1, No.1, June 2020, 
Tafkir: Interdisciplinary Journal of Islamic Education

Vol.1, No.1, June 2020, , DOI:

Hal: 54-71, E-ISSN :

tentang pembelajaran pendidikan agama islam kurikulum 2013 bagi anak-anak berkebutuhan khusus.

\section{PEMBAHASAN}

\section{Dinamika Kurikulum di Indonesia}

Kurikulum 2013 adalah kebijakan baru pemerintah dalam hal pendidikan berupa kurikulum terbaru yang kini diterapkan di Indonesia. Kurikulum ini merupakan pengembangan dari kurikulum sebelumnya yaitu kurikulum tingkat satuan pendidikan (KTSP) sejak 2006. Pengembangan kurikulum tentunya memuat beberapa perubahan yang diharapkan agar pendidikan di Indonesia semakin lebih baik lagi dan menyesuaikan kondisi serta kebutuhan masa depan.

Beberapa alasan mengapa pengembangan kurikulum ini dilakukan dijelaskan oleh wakil menteri pendidikan saat itu dalam file yang diunggah di website resminya, salah satunya ialah karena kurikulum sebelumnya (KTSP) masih terlalu banyak berfokus pada aspek kognitif peserta didik saja. Maka dari itu, kurikulum 2013 ini diharapkan mampu memberikan keseimbangan antara aspek kognitif, aspek afektif fan aspek psikomotorik peserta didik, sehingga pembelajaran yang terjadi dapat berjalan lancar dengan menyeimbangkan ketiga aspek. Hal tersebut menjadi konsep kurikulum 2013 .

Kurikulum 2013 juga dapat disebut sebagai kurikulum berbasis karakter. Kurikulum ini memiliki tujuan agar dapat mengubah sikap peserta didik menjadi lebih baik melalui nilai-nilai karakter di dalamnya. Pembelajaran dalam kurikulum 2013 harus mengembangkan ranah sikap (afektif) dan keterampilan (psikomotorik), tidak hanya ranah pengetahuan atau kognitif saja. Penekanan pembelajaran diarahkan pada penguasaan pengetahuan dan keterampilan yang dapat mengembangkan sikap spiritual dan sosial peserta didik ${ }^{9}$.

Pada kurikulum 2013, pembelajaran menggunakan pendekatan saintifik yaitu pendekatan yang menggunakan pendekatan ilmiah ${ }^{10}$. Pendekatan saintifik ini menekankan pada materi-materi yang berbasis pada fakta atau fenomena yang

${ }^{9}$ Imam Machali, 'Kebijakan Perubahan Kurikulum 2013 Dalam Menyongsong Indonesia Emas Tahun 2045', Jurnal Pendidikan Islam 3, no. 1 (2014): 82.

10 Pardomuan Nauli Josip Mario Sinambela, 'KURIKULUM 2013 DAN IMPLEMENTASINYA DALAM PEMBELAJARAN', E-Journal Universitas Negeri Medan, 2013, 19. 
dapat dijelaskan dengan logika atau penalaran tertentu dan bukan sebatas kira-kira. Dalam hal ini seorang pendidik berusaha menggiring peserta didik agar dapat berfikir secara kritis dan logis.

Pembelajaran yang diterapkan pada kurikulum 2013 ini secara umum memiliki lima langkah atau tahapan, yaitu mengamati (observasi), menanya, menalar, mencoba, dan menyimpulkan ${ }^{11}$. Peserta didik dituntut untuk menjadi lebih aktif sehingga pembelajaran yang terjadi ialah student center oriented dan bukan teacher center oriented.

Adapun model-model pembelajaran yang mendukung penerapan kurikulum 2013 diantaranya adalah 1) model pembelajaran berdasarkan masalah (Problem Based Learning) dan 2) model pembelajaran berbasis proyek (Project Baseed Learning).

Pada model pembelajaran berbasis masalah, peserta didik dihadapkan pada sebuah masalah yang bersifat top-down, yakni dari masalah yang kompleks dilanjut dengan masalah-masalah yang lebih spesifik dengan maksud dapat mencari solusi masalah kompleks tersebut. Dalam hal ini, pendidik hanya berperan sebagai fasilitator dan pembimbing. Peserta didik diharapkan dapat mencari informasi mengenai masalah tersebut dan mencari solusinya.

Model pembelajaran berbasis proyek adalah model pembelajaran yang menggunakan proyek/kegiatan sebagai media. Peserta didik melakukan eksplorasi, penilaian, interpretasi, sintesis, dan informasi untuk menghasilkan berbagai bentuk hasil belajar. Pendidik berperan sebagai fasilitator, pelatih, penasehat dan perantara

Pada dasarnya tidak hanya dua model diatas yang harus digunakan di dalam proses pembelajaran kurikulum 2013. Kurikulum 2013 mengharapkan adanya perubahan yakni peserta didik agar lebih aktif dalam kegiatan pembelajaran. Dengan demikian, maka pembelajaran akan terasa lebih bermakna pada diri peserta didik. Tidak hanya sekedar mendengarkan penjelasan dari guru saja. tetapi mereka dituntut untuk mencari dan mengkonstruksi sendiri pengetahuannya sehingga meningkatkan kualitas sumber daya manusia dan meningkatkan daya saing bangsa seiring dengan perkembangan ilmu pengetahuan, teknologi, dan seni

11 Sinambela, 20. 
Kurikulum 2013 menekankan pada proses pendidikan yang holistik sehingga menyentuh pada cakupan yang lebih luas yaitu ranah kognitif, afektif, dan psikomotor. Kurikulum 2013 mengklasifikasikannya dalam empat kompetensi inti yaitu kompetensi sikap sosial, sikap spiritual, pengetahuan, dan keterampilan ${ }^{12}$. Materi-materi disusun agar dapat mencapai empat kompetensi tersebut.

Pada kurikulum 2006 atau KTSP dinilai terlalu banyak dan membebankan peserta didik. Selain itu juga terdapat materi yang mirip pada satu mata pelajaran dengan mata pelajaran yang lain. Hal tersebut menjadi salah satu alasan perlunya perombakan materi pada kurikulum yang baru. Pada tingkat dasar, beberapa mata pelajaran dilebur menjadi satu yang disebut dengan tematik. Untuk tingkat menengah, materi-materi telah disusun oleh pemerintah berikut kompetensi dasar yang harus ditempuh peserta didik.

Untuk mencapai tujuan adanya kurikulum 2013, maka tidak hanya proses pembelajaran dan materi saja yang perlu adanya perbaikan. Penilaian adalah hal yang sangat penting untuk dikoreksi agar pembelajaran benar-benar mencapai tiga aspek secara merata dan tidak hanya condong ke aspek kognitif saja. Penilaian juga memiliki peran yang besar dalam menentukan kesuksesan pendidikan. Penilaian yang baik memberikan dampak pada proses pembelajaran dan menjadi rujukan untuk kebijakan lain kedepannya ${ }^{13}$.

Pada Kurikulum 2013, penilaian diatur dalam Permendikbud Nomor 66 Tahun 2013 tentang Standar Penilaian Pendidikan meliputi penilaian otentik, penilaian diri, penilaian berbasis portofolio, ulangan harian, ulangan tengah semester, ulangan akhir, ujian tingkat kompetensi, ujian mutu tingkat kompetensi, ujian nasional dan ujian sekolah/madrasah. Penilaian-penilaian tersebut dilakukan oleh pendidik, satuan pendidikan dan pemerintah.

Target belajar pada kurikulum 2013 bukan hanya pada kompetensi, tetapi juga pembangunan karakter peserta didik ${ }^{14}$. Hal ini berarti pada kurikulum 2013

12 Hari Setiadi, 'Pelaksanaan Penilaian Pada Kurikulum 2013', Jurnal Penelitian Dan Evaluasi Pendidikan 20, no. 2 (2016): 167, https://doi.org/10.21831/pep.v20i2.7173.

13 Setiadi, 167.

14 A.A.I.N Marhaeni and L.P. Artini, 'Asesmen Autentik Dan Pendidikan Bermakna: Implementasi Kurikulum 2013', Jurnal Pendidikan Indonesia 4, no. 1 (2015): 501, https://doi.org/10.1300/J104v33n03_08. 
peserta didik tidak hanya dinilai pada kompetensi-kompetensi yang berhasil ia capai atau pada hasil akhirnya saja, melainkan juga pada bagaimana proses ia belajar.

Sebagaimana dijelaskan bahwa kurikulum 2013 menekankan pula pada keseimbangan pada tiga aspek yakni kognitif, afektif dan psikomotorik pada peserta didik, maka penilaian dirancang pula sedemikian rupa. Domain penilaian dalam Kurikulum 2013 meliputi domain spiritual, sikap sosial, pengetahuan, dan keterampilan. Secara lebih umum dapat dikategorikan menjadi tiga domain yaitu kognitif (pengetahuan), afektif (sikap sosial dan spiritual), dan psikomotor (keterampilan) ${ }^{15}$.

Kurikulum 2013 sesuai dengan penilaian otentik. Penilaian/asesmen otentik adalah proses pengumpulan informasi oleh pendidik tentang perkembangan dan pencapaian pembelajaran yang dilakukan oleh peserta didik melalui berbagai teknik yang mampu mengungkapkan, membuktikan atau menunjukkan secara tepat bahwa tujuan pembelajaran telah benar-benar dikuasai dan dicapai ${ }^{16}$.

Dengan penilaian autentik, peserta didik diukur dan dinilai dari proses dan produk belajarnya. Hal tersebut tentu berbeda dengan system penilaian yang diterapkan sebelumnya yang mana hanya ditekankan pada produk saja. Melalui penilaian autentik, dapat mengembangkan keempat kompetensi inti yang mencakup kompetensi religius, sikap sosial, pengetahuan dan keterampilan yang ada dalam kurikulum 2013. Selain itu, dengan penilaian ini, peserta didik dapat menilai dirinya sendiri sehingga dapat mengembangkan rasa bertanggungjawab dalam belajar dan dapat membangun pembiasaan untuk berfikir logis, obyektif, kritis dan kreatif ${ }^{17}$.

\section{Pembelajaran Pendidikan Agama Islam (PAI)}

Pendidikan agama islam merupakan salah satu mata pelajaran wajib yang harus ditempuh bagi peserta didik yang beragama islam. Dalam tiap jenjang pendidikan mulai dari taman kanak-kanak, sekolah dasar, sekolah menengah pertama, sekolah menengah atas hingga perguruan tinggi pasti terdapat mata

${ }^{15}$ Setiadi, 'Pelaksanaan Penilaian Pada Kurikulum 2013', 169.

${ }^{16}$ Muzlikhatun Umami, 'Penilaian Autentik Pembelajaran Pendidikan Agama Islam Dan Budi Pekerti Dalam Kurikulum 2013', Jurnal Kependidikan 6, no. 2 (2018): 226.

17 Marhaeni and Artini, 'Asesmen Autentik Dan Pendidikan Bermakna : Implementasi Kurikulum 2013', 503.

Vol.1, No.1, June 2020, 
pelajaran agama. Di dalam kurikulum 2013, mata pelajaran ini kini bernama Pendidikan Agama Islam dan Budi Pekerti.

Dalam Konferensi Pendidikan Islam se Dunia (World Conference of Islamic Education) pada tahun 1977 bahwa pendidikan Islam mencakup pengertian tarbiyah, ta'lim dan ta'dib'18. Ta'lim memiliki makna pendidikan yang berfokus pada pengetahuan, dan ta'dib bermakna pendidikan yang lebih berfokus pada akhlak. Sementara itu tarbiyah memiliki pengertian yang lebih luas diantara dua istilah yang lain.

Pendidikan agama islam oleh tim Dosen UIN Sunan Ampel diartikan sebagai suatu proses, upaya dan cara mendidikkan ajaran agama Islam agar menjadi anutan dan pandangan hidup bagi seorang muslim ${ }^{19}$. Sementara itu, pendidikan agama islam menurut Zakiyah Darajat adalah suatu usaha untuk membina dan mengasuh peserta didik agar senantiasa dapat memahami ajaran islam secara menyeluruh, lalu menghayati tujuan, yang pada akhirnya dapat mengamalkan serta menjadikan islam sebagai pandangan hidup ${ }^{20}$.

Demikian penulis menyimpulkan bahwa pendidikan agama islam adalah suatu usaha sadar dan terencana untuk memasukkan ajaran-ajaran agama islam melalui pembelajaran dengan harapan perkembangan fisik dan psikis peserta didik dapat berkembang sesuai dengan ajaran Islam menuju terbentuknya kepribadian muslim yang utuh, berkaraktek dan berakhlak mulia.

Adapun materi atau ruang lingkup pendidikan agama islam berasal dari sumber pokok yaitu Al-Qur'an dan Hadist. Selain itu juga beraal dari istinbat dan ijtihad para 'ulama, sehingga ajaran-ajaran pokok yang masih bersifat umum dapat dijelaskan lebih rinci dan detail. Materi-materi pendidikan agama islam memuat tentang:

a) Hubungan manusia dengan Tuhan. Membentuk manusia Indonesia yang beriman dan bertakwa kepada Allah Swt serta berakhlak mulia dan berbudi pekerti luhur.

${ }^{18}$ M. Hajar Dewantoro, 'Pengembangan Kurikulum Pendidikan Agama Islam', JPI FIAI IX (2003): 49.

${ }^{19}$ Dewantoro, 49-50.

20 Irfad Faiq Abdillah, 'Implementasi Kurikulum 2013 Pada Mata Pelajaran Pendidikan Agama Islam Di SMP Negeri II Puger' (UIN Maulana Malik Ibrahim, 2016), 62.

Analisis Pembelajaran Pendidikan Agama Islam,.. 
b) Hubungan manusia dengan diri sendiri. Menghargai dan menghormati diri sendiri yang berlandaskan pada nilai-nilai keimanan dan ketakwaan.

c) Hubungan manusia dengan sesama. Menjaga kedamaian dan kerukunan hubungan inter dan antar umat beragama.

d) Hubungan manusia dengan lingkungan alam. Penyesuaian mental keislaman terhadap lingkungan fisik dan sosial.

\section{Anak Berkebutuhan Khusus}

Terdapat beberapa istilah bagi anak-anak yang berbeda dengan yang lain pada umumnya, diantaranya ialah anak cacat, anak tuna, anak berkelainan, anak menyimpang, dan anak luar biasa. Istilah anak berkebutuhan khusus adalah istilah terbaru yang digunakan dan merupakan alih bahasa dari child with special meeds yang digunakan secara internasional ${ }^{21}$. Istilah anak berkebutuhan khusus ini dirasa lebih tepat karena tidak hanya yang memiliki kekurangan yang perlu penanganan khusus, melainkan yang memiliki kelebihan juga membutuhkan penanganan khusus di dalam bidang pendidikan.

Definisi anak berkebutuhan khusus menurut Mangunsong ialah anak yang menyimpang dari rata-rata anak normal dalam hal : ciri-ciri mental, kemampuan sensorik, fisik dan neuromuskular, perilaku sosial dan emosional, kemampuan berkomunikasi maupun kombinasi dua atau lebih dari hal-hal diatas; sejauh ia memerlukan modifikasi dari tugas-tugas sekolah, metode belajar atau pelayanan terkait lainnya, yang ditujukan untuk mengembangkan potensi atau kapasitasnya secara maksimal22.

Menurut Gearheart, anak dengan kebutuhan khusus adalah anak yang memerlukan persyaratan pendidikan yang berbeda dari rata-rata anak normal, dan untuk belajar secara efektif memerlukan program, pelayanan, fasilitas, dan materi khusus ${ }^{23}$. Anak-anak berkebutuhan khusus pada hakikatnya adalah anak-anak yang memiliki keunikan tersendiri dalam jenis dan karakteristiknya, yang mana membuat mereka berbeda dengan anak-anak normal pada umumnya ${ }^{24}$. Keunikan ini memiliki ragam yang banyak sehingga terkadang menyulitkan pendidik karena

${ }^{21}$ Suparno, Pendidikan Anak Berkebutuhan Khusus, n.d., 2.

${ }^{22}$ Nur Eva, Psikologi Anak Berkebutuhan Khusus (Malang: Fakultas Pendidikan Psikologi Univeritas Negeri Malang, 2015), 1.

${ }^{23}$ Eva, 1.

${ }^{24}$ Suparno, Pendidikan Anak Berkebutuhan Khusus, 1. 
Tafkir: Interdisciplinary Journal of Islamic Education

Vol.1, No.1, June 2020, , DOI:

Hal: 54-71, E-ISSN :

masing-masing dari ragam tersebut perlu kebutuhan yang berbeda. Adapun keunikan tersebut dapat dikelompokkan sebagai berikut ${ }^{25}$ :

a. Kelainan mental, terdiri atas :

- Mental Tinggi. Anak-anak yang memiliki intelektual (IQ) di atas rerata normal. Mereka memiliki kreativitas dan bertanggung jawab terhadap tugas.

- Mental Rendah. Terbagi menjadi dua kelompok yaitu anak lamban belajar yang memiliki IQ antara 70-90, dan yang memiliki IQ dibawah 70 yang dikenal dengan sebutan anak berkebutuhan khusus.

- Berkesulitan Belajar Spesifik. Yaitu anak yang memiliki kapasitas intelektual normal keatas tapi memiliki prestasi belajar rendah pada bidang akademik tertentu.

b. Kelainan Fisik, meliputi :

- Kelainan Tubuh (Tunadaksa). Yaitu anak-anak yang memiliki kondisi tubuh yang berbeda yang menghambat mereka berinteraksi dan bersosialisasi. Contohnya ialah mereka yan mengalami kelumpuhan karena polio, gangguan pada fungsi saraf otot yang disebabkan kelayuhan otak (cerebral palsy), dan adanya kehilangan organ tubuh (amputasi).

- Kelainan Indera Penglihatan (Tunanetra). Mereka yang kehilangan kemampuan penglihatan meskipun telah dikoreksi atau dibantu dengan penggunaan lensa. Tunanetra dibagi menjadi dua yaitu buta dan low vision.

- Kelainan Indera Pendengaran (Tunarungu). Tunarungu juga dikelompokkan menjadi dua yaitu tuli dan kurang dengar.

- Kelainan Wicara. Mereka yang mengalami kesulitan untuk mengungkapkan pikiran melalui bahasa verbal. Kelainan ini dapat bersifat fungsional dimana mungkin disebabkan karena ketunarunguan.

c. Kelainan Emosi

- Gangguan Perilaku, cirinya antara lain : mengganggu di kelas, tidak sabaran atau terlalu cepat bereaksi, tidak mengahrgai, menyalahkan orang

${ }^{25}$ Suparno, 12-15.

Analisis Pembelajaran Pendidikan Agama Islam,.. 
Dinda Zulaikhah, Andika Aprilianto

lain, kecemasan terhadap prestasi di sekolah, dependen terhadap orang lain, pemahaman yang lemah, melamum, tidak ada perhatian dan menarik diri.

- Gangguan Konsentrasi. Gejala dari gangguan konsentrasi berlangsung paling sedikit 6 bulan, ketidakmampuan untuk beradaptasi dan tingkat perkembangannya tidak konsisten.

- Anak Hiperaktif. Cirinya ialah periaku tidak bisa diam, aktivitas motoric yang tinggi, mudah buyar perhatian, toleransi yang rendah terhadap frustasi, berbuat tanpa dipikir akibatnya.

Adapun pengelompokan atau klasifikasi anak-anak berkebutuhan khusus oleh direktorat Pembinaan Sekolah Luar Biasa (PSLB) untuk aplikasi jenis sekolah luar biasa di lapangan adalah sebagai berikut :

1. Tunanetra

2. Tunarungu

3. Tunagrahita/Berkebutuhan Khusus (Down Syndrome)

- $\quad$ C: berkebutuhan khusus ringan $(\mathrm{IQ}=50-70)$

- $\quad$ C1 : berkebutuhan khusus sedang $(\mathrm{IQ}=25-50)$

- $\quad$ C2 : berkebutuhan khusus berat $(\mathrm{IQ}<25)$

4. Tunadaksa

- D : Tunadaksa ringan

- D1 : Tunadaksa sedang

5. Tunalaras (Dysruptive)

6. Tunawicara

7. Tunaganda

8. HIV AIDS

9. Gifted : potensi kecerdasan Istimewa (IQ $>125)$

10. Talented : potensi bakat istimewa (multiple intelligences)

11. Kesulitas belajar (hiperaktif, dyslexia/baca, dysgraphia/tulis, dyscalculia/hitung, dysphasia/bicara, dyspraxia/motoric)

12. Lambat belajar $(\mathrm{IQ}=70-90)$

13. Autis

14. Korban penyalahgunaan narkoba 


\section{Indigo}

Berdasarkan klasifikasi diatas, pendidikan bagi anak-anak berkebutuhan khusus telah diatur oleh pemerintah dengan adanya pendidikan luar biasa. Pendidikan luar biasa (PLB) memisahkan antara anak luar biasa dengan anak lain pada umumnya, yaitu untuk keperluan pembelajaran. Hal tersebut bukan berarti pembedaan dalam hal negatif atau diskriminasi namun dimaksudkan untuk meningkatkan efektivitas dan efisiensi dalam mencapai tujuan pembelajaran ${ }^{26}$.

Pendidikan luar biasa terwujud dalam Sekolah Luar Biasa (SLB). Selain itu juga terdapat pendidikan inklusif yang terwujud dalam sekolah inklusif, yakni sekolah yang memberikan kesempatan bagi anak-anak berkebutuhan khusus untuk dapat belajar bersama dengan peserta didik reguler. Dalam pendidikan inklusif ini, meyakini bahwa seharusnya pendidikan berdifat adil dan tidak diskriminatif. Semua peserta didik hendaknya dapat berbagi dengan temannya dan menghargai perbedaan diantara mereka ${ }^{27}$. Ini merupakan kelebihan sekolah inklusif yang mana membuat anak-anak berkebutuhan khusus memiliki kesempatan untuk berbaur dengan anak-anak normal lainnya. Namun juga memiliki dampak negative bila saja teman-temannya kurang menghargainya, maka akan semakin merendahkan kepercayaan dirinya dan membuatnya tidak nyaman belajar.

\section{Analisis Kurikulum 2013 pada Materi Pendidikan Agama Islam untuk Anak Berkebutuhan Khusus}

Sebagai sebuah lembaga pendidikan formal, pendidikan khusus yang mencakup sekolah luar biasa dan sekolah inklusif tentu membutuhkan kurikulum dalam pelaksanaan proses belajar mengajarnya. Pada perkembangan pendidikan di Indonesia, kurikulum yang terbaru yang digunakan adalah kurikulum 2013. Proses pembelajaran yang merupakan kunci dalam sebuah pendidikan tentunya harus sangat diperhatikan. Pembelajaran merupakan interaksi antara guru dan murid dalam suatu kelas atau diluar kelas sehingga terjadi proses transfer ilmu. Komponen pembelajaran setidaknya terdiri dari guru, murid, materi dan evaluasi.

\footnotetext{
${ }^{26} \mathrm{M}$ Maftuhin and A. Jauhar Fuad, 'PEMBELAJARAN PENDIDIKAN AGAMA ISLAM PADA ANAK BERKEBUTUHAN KHUSUS', Journal An-Nafs 3, no. 1 (2018): 78.

27 Putri Nurina, Pendidikan Agama Islam Bagi Siswa Autis Pada Sekolah Inklusif (Tangerang: Young Progressive Muslim, 2015), 41.
} 
Pada sekolah luar biasa, guru memiliki peran besar karena pada dasarnya guru yang akan mentransferkan ilmu kepada para murid. Selain itu evaluasi terhadap perkembangan murid juga dilakukan oleh guru. Seorang guru dituntut untuk dapat membuat siswa senantiasa nyaman dan termotivasi untuk belajar. Guru sangat diharapkan dapat memberikan hasil yang memuaskan selama mereka mengajar. Namun tentu tidaklah mudah bagi guru SLB. Tantangan mereka semakin besar dibandingkan guru-guru yang mengajar murid regular. Menjadi guru SLB dibutuhkan kesabaran dan ketelatenan yang tiada batas.

Penelitian oleh Dyane Trikora Wardhani tahun 2012 menyebutkan bahwa cukup banyak guru SLB yang mengalami Burnout, yakni kondisi emosional dimana seseorang merasa lelah dan jenuh secara mental ataupun fisik sebagai akibat tuntutan pekerjaan yang meningkat ${ }^{28}$. Hal tersebut dipicu oleh banyaknya tuntutan yang ditanggung seorang guru SLB, namun di lapangan tentu sangat tidak mudah untuk berhadapan dan membimbing anak-anak berkebutuhan khusus tersebut. Besarnya beban tuntutan namun tidak diiringi dengan sarana-prasarana dan kesejahteraan guru membuat banyaknya guru yang mengalami burnout.

Pembelajaran PAI hendaknya menggunakan pendekatan individu (individual approach) yang mana guru harus mengetahui dan memiliki data lengkap terkait siswa yang diajarnya ${ }^{29}$. Hal tersebut akan memudahkan guru dalam melaksanakan tugasnya karena mereka memahami kebutuhan masing-masing siswa, selain itu juga dapat memudahkan pemantauan dan penilaian terhadap perkembangan masing-masing murid seperti yang dikehendaki dalam kurikulum 2013. Adapun materi pembelajaran pada mata pelajaran PAI bagi anak berkebutuhan khusus telah ditetapkan pemerintah yakni berupa KI KD yang tertulis dalam permendikbud.

Komponen pembelajaran selanjutnya ialah peserta didik. Sebagai seorang siswa yang berbeda dengan pada umumnya, anak-anak berkebutuhan khusus tentu memerlukan perlakuan-perlakuan yang lebih khusus dibandingkan biasanya. Pada penyampaian materi oleh guru, anak-anak dengan ketunaan biasanya memiliki daya fokus yang lebih rendah juga cenderung lebih cepat lelah dibandingkan

${ }^{28}$ Dayne Trikora Wardhani, ‘Burnout Di Kalangan Guru Pendidikan Luar Biasa Di Kota Bandung', Jurnal Psikologi Undip 11, no. 1 (2012): 75, https:/ / doi.org/10.14710/jpu.11.1.10.

${ }^{29}$ Arif Wahyudi and Miftachul Huda, 'Internalization of Islamic Values for Students with Special Needs in Special School Education Institutions (SLB)', AL-HAYAT: Journal of Islamic Education 3, no. 1 (2019): 95, https://doi.org/10.35723/ajie.v3i1.55.

Vol.1, No.1, June 2020, 
Tafkir: Interdisciplinary Journal of Islamic Education

Vol.1, No.1, June 2020, , DOI:

Hal: 54-71, E-ISSN :

dengan anak-anak pada umumnya ${ }^{30}$. Hal ini sesuai dengan hasil wawancara bersama guru PAI di SD-LB Yayasan Rehabilitasi Tuna Rungu Wicara yang dilakukan Gustafi.

Singkatnya waktu pembelajaran agama islam di kelas tentunya kurang memberikan hasil yang maksimal, padahal pendidikan agama sangat penting sebagai pondasi manusia dalam menjalani hidup. Untuk mengatasi hal tersebut, dalam penelitian Gustafi tercetus sebuah ide akan penggunakan aplikasi pembelajaran pada smartphone untuk menunjang proses pembelajaran agama islam.

Peserta didik dengan kebutuhan khusus tentunya membutuhkan layanan yang sedikit berbeda dengan anak pada umumnya. Pembelajaran menggunakan kurikulum 2013 yang mana berorientasi pada siswa, artinya siswa diharapkan dapat aktif, inovatif dan guru hanya sebagai fasilitator. Ini dapat diterapkan juga pada sekolah berkebutuhan khusus. Dalam praktiknya di SMPLB Muhammadiyah Sidayu Gresik, pembelajaran umumnya menggunakan metode individual, yakni diawali dengan pemaparan materi oleh guru di depan kelas kemudian dilanjutkan dengan guru menghampiri satu persatu muridnya untuk memastikan kepahaman mereka tentang materi di hari itu ${ }^{31}$. Pada pembelajaran PAI biasa diawali dengan pembacaan surat-surat pendek bersama sehingga anak bisa terbiasa mendengarkan dan membaca surat-surat pendek.

Terdapat pula model pembelajaran lain yang telah diterapkan oleh sekolah luar biasa Al-Achsaniyyah yakni menerapkan dua model pembelajaran; Classical Model dan One on One Classi2. Classical class merupakan kelas seperti pada umumnya, dimana seorang guru mengajar kepada sejumlah murid. Dalam AlAchsaniyyah institusi model pembelajaran ini hanya berlangsung selama 3 bulan sejak pertama kali anak-anak berkebutuhan khusus (autis) ini masuk pada lembaga

${ }^{30}$ Muhammad Fauzan Gustafi, 'LEARNING APPLICATION OF DAILY PRAYER FOR DEAF CHILDREN SD-LB YAYASAN REHABILITASI TUNA RUNGU WICARA' (Universitas Muhammadiyah Surakarta, 2017), 3.

31 Hernik Rosyidatul Baroroh, 'IMPLEMENTASI KURIKULUM 2013 PADA PEMBELAJARAN PAI BAGI ANAK BERKEBUTUHAN KHUSUS DI SLB MUHAMMADIYAH SIDAYU GRESIK', Jurnal Tamaddun XXI, no. 1 (2020): 98.

${ }^{32}$ M Saifullah Rohman, 'Islamic Boarding School and Autism : Bringing A Just Religious Education for Child with Autism and Special Need', The 9th International Graduate Students and Scholars' Conference in Indonesia (IGSSCI) 9, no. 10 (2017): 879.

Analisis Pembelajaran Pendidikan Agama Islam,.. 
pendidikan Al-Achsaniyyah. Adapun model one on one class adalah pembelajaran seperti halnya pembelajaran privat. Pada pembelajaran ini, seorang guru hanya mengajar seorang murid dalam waktu satu jam. Kemudian di jam lain, murid tersebut akan kembali belajar secara privat juga namun dengan guru yang lain. Dengan model one on one ini, siswa dapat berekspresi dan berkreasi dengan lebih mudah diarahkan dan diawasi ketika mereka melakukan suatu proyek. Pengawasan dan perhatian yang penuh ini tentunya akan lebih memudahkan dalam membentuk dan mengarahkan mereka.

Pembelajaran yang student center oriented tentu memang lebih menyenangkan, berkesan dan bermakna pada peserta didik dibandingkan pembelajaran yang teacher oriented. Hal tersebut berlaku juga pada anak-anak berkebutuhan khusus. Mereka lebih senang dan aktif dalam pembelajaran. Anakanak berkebutuhan khusus sangat senang ketika ditunjukkan gambar-gambar serta diinstruksikan untuk menulis, mengamati dan melakukan praktik atau demonstrasi ${ }^{33}$.

Adapun tantangan seorang pendidik pada sekolah SLB selain dibutuhkan kesabaran dan ketelatenan yang lebih besar, mereka juga harus menemukan metode yang tepat sehingga anak-anak dapat memahami materi beserta dapat mempraktikkan atau mengamalkannya dalam kehidupan. Meskipun materi telah dipadatkan dan dapat menyesuaikan kondisi peserta didik, tetap saja dalam menanamkan ajaran islam diperlukan adanya pembiasaan sehingga anak-anak dengan kebutuhan khusus dapat terbiasa mengamalkan syariat islam. Evaluasi pembelajaran sangat diperlukan guna mengetahui sejauh mana hasil pembelajaran yang telah dilalui.

Evaluasi pembelajaran umumnya dilakukan setiap pertemuan sebagai nilai harian dan saat ujian tengah semester serta akhir semester. Dalam kurikulum 2013 evaluasi dilakukan dengan penilaian autentik. Penilaian autentik adalah proses pengumpulan informasi tentang perkembangan dan pencapaian pembelajaran yang dilakukan oleh peserta didik melalui berbagai teknik yang mampu mengungkapkan, membuktikan atau menunjukkan secara tepat bahwa tujuan

33 Baroroh, 'IMPLEMENTASI KURIKULUM 2013 PADA PEMBELAJARAN PAI BAGI ANAK BERKEBUTUHAN KHUSUS DI SLB MUHAMMADIYAH SIDAYU GRESIK', 99.

Vol.1, No.1, June 2020, 
pembelajaran telah benar-benar dikuasai dan dicapai ${ }^{34}$. Hal ini sesuai dengan Permendikbud No.66 bahwasanya penilaian harus dilakukan secara komprehensif yakni dari proses hingga keluar (output) pembelajaran.

Dari segi kognitif, tentu pada pendidikan reguler diterapkan system acuan nilai minimal atau disebut juga dengan KKM (kriteria ketuntasan minimal). Sekolah biasanya akan menetapkan KKM yang sama pada semua peserta didik. Namun dalam pendidikan khusus cocok dan lebih baik bila menerapkan KKM yang berbeda pada tiap peserta didik. Hal ini sesuai dengan Ilahi yang berpendapat bahwa jenis evaluasi yang akan diberikan pada anak-anak berkebutuhan khusus hendaknya disesuaikan dengan tingkat kemampuan dan kecerdasannya dalam menerima materi pelajaran ${ }^{35}$.

\section{KESIMPULAN}

Pembelajaran pendidikan agama islam (PAI) pada pendidikan khusus tidak jauh berbeda dengan pembelajaran PAI pada pendidika reguler. Komponenkomponen pembelajaran pada pendidikan khusus setidaknya terdiri dari guru, siswa, materi, dan evaluasi. Sebagai guru di institusi pendidikan khusus, diperlukan kesabaran dan ketelatenan yang besar juga motivasi mengabdi yang tinggi agar tidak mengalami burnout layaknya kebanyakan guru SLB lainnya. Adapun materi bagi anak-anak berkebutuhan khusus telah memiliki kurikulum sendiri bagi pendidikan khusus. Materi lebih dipadatkan dan disederhanakan dan masih bisa disesuaikan lagi oleh guru sesuai kondisi peserta didik. Dan dalam hal evaluasi, pada dasarnya masih sama dengan pendidikan reguler, dapat berupa tes tulis, non tulis, lisan atau perbuatan. Namun dalam pendidikan khusus dapat diterapkan KKM yang berbeda pada tiap anak menyesuaikan dengan kemampuan dan kecerdasan mereka dalam menerima pelajaran.

${ }^{34}$ Umi Salamah, 'Penjaminan Mutu Penilaian Pendidikan', EVALUASI 2, no. 1 (2018): 281.

35 Frigitania Zindy Isadona, 'Proses Penilaian Dan Evaluasi Pembelajaran Yang Dilakukan Pada ABK Di Sekolah Dasar Inklusif' (Universitas Sanata Dharma, 2019), 26. 


\section{REFERENSI}

Abdillah, Irfad Faiq. 'Implementasi Kurikulum 2013 Pada Mata Pelajaran Pendidikan Agama Islam Di SMP Negeri II Puger'. UIN Maulana Malik Ibrahim, 2016.

Abidin, Yunus. Desain Sistem Pembelajaran Dalam Konteks Kurikulum 2013. Cetakan kesatu. Bandung: Refika Aditama, 2014.

Baroroh, Hernik Rosyidatul. 'IMPLEMENTASI KURIKULUM 2013 PADA PEMBELAJARAN PAI BAGI ANAK BERKEBUTUHAN KHUSUS DI SLB MUHAMMADIYAH SIDAYU GRESIK'. Jurnal Tamaddun XXI, no. 1 (2020): 91-102.

Dewantoro, M. Hajar. 'Pengembangan Kurikulum Pendidikan Agama Islam'. JPI FIAI IX (2003).

Eva, Nur. Psikologi Anak Berkebutuhan Khusus. Malang: Fakultas Pendidikan Psikologi Univeritas Negeri Malang, 2015.

Gustafi, Muhammad Fauzan. 'LEARNING APPLICATION OF DAILY PRAYER FOR DEAF CHILDREN SD-LB YAYASAN REHABILITASI TUNA RUNGU WICARA'. Universitas Muhammadiyah Surakarta, 2017.

Idi, Abdullah. Pengembangan kurikulum: teori dan praktik. 2nd ed. Jakarta: Raja Grafindo Persada, 2016.

Indana, Nurul. ‘Penerapan Kurikulum Terintegrasi Dalam Mengembangkan Mutu Belajar Siswa (Studi Kasus Di Sma Darul 'Ulum 1 Unggulan Bppt Jombang)'. Nidhomul Haq : Jurnal Manajemen Pendidikan Islam 3, no. 2 (17 October 2018): 121-47. https:/ / doi.org/10.31538/ndh.v3i2.80.

Isadona, Frigitania Zindy. 'Proses Penilaian Dan Evaluasi Pembelajaran Yang Dilakukan Pada ABK Di Sekolah Dasar Inklusif'. Universitas Sanata Dharma, 2019.

Ma`arif, Muhammad Anas, and Ari Kartiko. 'Fenomenologi Hukuman di Pesantren: Analisis Tata Tertib Santri Pondok Pesantren Daruttaqwa Gresik'. Nadwa 12, no. 1 (22 June 2018): 181-96. https://doi.org/10.21580/nw.2018.12.1.1862.

Ma`arif, Muhammad Anas, and Ibnu Rusydi. 'IMPLEMENTASI PENDIDIKAN HOLISTIK DI PONDOK PESANTREN AMANATUL UMMAH MOJOKERTO'. EDUKASI: Jurnal Penelitian Pendidikan Agama Dan Keagamaan 18, no. 1 (27 April 2020). https://doi.org/10.32729/edukasi.v18i1.598.

Maarif, Muhammad Anas, and Muhammad Husnur Rofiq. 'Pola Pengembangan Kurikulum Pendidikan Pesantren Berkarakter: Studi Implementasi Pendidikan Berkarakter di Pondok Pesantren Nurul Ummah Mojokerto' 13 (2018): 16.

Machali, Imam. 'Kebijakan Perubahan Kurikulum 2013 Dalam Menyongsong Indonesia Emas Tahun 2045'. Jurnal Pendidikan Islam 3, no. 1 (2014). 
Maftuhin, M, and A. Jauhar Fuad. 'PEMBELAJARAN PENDIDIKAN AGAMA ISLAM PADA ANAK BERKEBUTUHAN KHUSUS'. Journal An-Nafs 3, no. 1 (2018): 76-90.

Marhaeni, A.A.I.N, and L.P. Artini. 'Asesmen Autentik Dan Pendidikan Bermakna : Implementasi Kurikulum 2013'. Jurnal Pendidikan Indonesia 4, no. 1 (2015). https://doi.org/10.1300/J104v33n03_08.

Nurina, Putri. Pendidikan Agama Islam Bagi Siswa Autis Pada Sekolah Inklusif. Tangerang: Young Progressive Muslim, 2015.

Rahmat, Munawar. 'Model Perkuliahan Pendidikan Agama Islam Yang Damai, Moderat, dan Toleran'. Nadwa 12, no. 1 (22 June 2018): 39-64. https://doi.org/10.21580/nw.2018.12.1.2180.

Rahmat, Rahmat. 'Liberalisme Dalam Pendidikan Islam (Implikasinya Terhadap Sistem Pembelajaran Agama Islam Di Sekolah)'. Nidhomul Haq: Jurnal Manajemen Pendidikan Islam 1, no. 2 (2016): 70-88. https:// doi.org/10.31538/ndh.v1i2.10.

Rofiq, Muhammad Husnur, and Prastio Surya. 'Model Pembentukan Karakter Berbasis Tasawuf Akhlaqi'. Ilmuna: Jurnal Studi Pendidikan Agama Islam 1, no. 2

(2019):

65-81. https://jurnal.stituwjombang.ac.id/index.php/ilmuna/article/view/109.

Rohman, M Saifullah. 'Islamic Boarding School and Autism: Bringing A Just Religious Education for Child with Autism and Special Need'. The 9th International Graduate Students and Scholars' Conference in Indonesia (IGSSCI) 9, no. 10 (2017).

Salamah, Umi. 'Penjaminan Mutu Penilaian Pendidikan'. EVALUASI 2, no. 1 (2018): 274-93.

Setiadi, Hari. 'Pelaksanaan Penilaian Pada Kurikulum 2013'. Jurnal Penelitian Dan Evaluasi Pendidikan 20, no. 2 (2016). https://doi.org/10.21831/pep.v20i2.7173.

Sinambela, Pardomuan Nauli Josip Mario. 'KURIKULUM 2013 DAN IMPLEMENTASINYA DALAM PEMBELAJARAN'. E-Journal Universitas Negeri Medan, 2013.

Suparno. Pendidikan Anak Berkebutuhan Khusus, n.d.

Umami, Muzlikhatun. 'Penilaian Autentik Pembelajaran Pendidikan Agama Islam Dan Budi Pekerti Dalam Kurikulum 2013'. Jurnal Kependidikan 6, no. 2 (2018).

Wahyudi, Arif, and Miftachul Huda. 'Internalization of Islamic Values for Students with Special Needs in Special School Education Institutions (SLB)'. ALHAYAT: Journal of Islamic Education 3, no. 1 (2019). https://doi.org/10.35723/ajie.v3i1.55.

Wardhani, Dayne Trikora. 'Burnout Di Kalangan Guru Pendidikan Luar Biasa Di Kota Bandung'. Jurnal Psikologi Undip 11, no. 1 (2012): 10. https://doi.org/10.14710/jpu.11.1.10. 